\title{
Evaluating the effect of ammonia-water dilution pressure and its density on thermodynamic performance of combined cycles by the energy-exergy analysis approach
}

\author{
Soheil Mohtaram*, Ji Lin**, Wen Chen***, M. Amin Nikbakht**** \\ *State key laboratory of Hydrology-Water Recourses and Hydraulic Engineering, International Center for Simulation \\ Software in Engineering and Sciences, College of Mechanics and Materials, Hohai University, Nanjing 210098, Jiangsu, \\ China, E-mail: Soheilmohtaram@gmail.com \\ **State key laboratory of Hydrology-Water Recourses and Hydraulic Engineering, International Center for Simulation \\ Software in Engineering and Sciences, College of Mechanics and Materials, Hohai University, Nanjing 210098, Jiangsu, \\ China, E-mail: linji861103@126.com \\ ***State key laboratory of Hydrology-Water Recourses and Hydraulic Engineering, International Center for Simulation \\ Software in Engineering and Sciences, College of Mechanics and Materials, Hohai University, Nanjing 210098, Jiangsu, \\ China, Corresponding Author's e-mail: chenwen@hhu.edu.cn \\ ****Department of Mechanical Engineering, Khomeinishahr Branch, Islamic Azad University, Isfahan, Iran, \\ E-mail: Amin.nikbakht88@gmail.com
}

cross $^{\text {ref }}$ http://dx.doi.org/10.5755/j01.mech.23.2.18110

\section{Introduction}

In power plants, in order to achieve a convenient and improvement chemical control in a boiler of cycle system [1-4], some implementation processes are required in different parts of the boiler: pressure of dilution in the boiler [5-6] and the density of liquid [7] in the whole cycle system. This indicates that if any problem appears in any segments, whatever the conditions for the rest of the cycle system, the complete system will not work properly. It is known that one of the most important and vulnerable part of power plants is the boiler which owns the function to convert chemical energy of fuel into heat energy and transfer the achieved energy into the working fluid. For this purpose, the well controlling of the boiler has a great importance in preventing scale formation on heat transfer surfaces and corrosion in equipment thermal cycle system. Some chemical control methods can be viewed in [8-12]: AVT: ALL Volatile treatment, NWT: Neutral water treatment, CWT: Combined water treatment, Water Quality Control, Executive control actions from (AVT) to (CWT) in the combined cycle power plant

The use of combined water treatment or multiple mixture fluid is one of the most important progresses of combined cycle systems. As for an operating fluid, we apply the organic fluid such as the ammonia-water and the lithium-bromide. Combined cycle which employs binary mixture fluids has better capacity for electricity generation by low temperature sources [13-15]. It has been determined that among cycles with binary mixture fluids, Lorenz cycle maintains the most effective performance in temperature with fixed range [16] and the performance is due to the inconstant boiling and condensation of binary fluids. After selecting the appropriate dilution by the above mentioned methods, it should be noted that the soluble should be entered into the boiler with a suitable pressure and the exact concentration of fluid of the cycle. The performance and destruction exergy percentage of cycle will be improved by proper selections of pressure and fluid.

Ammonia water combined cycle is studied in terms of Exergy and the mentioned cycle evaluated through latent heat is modeled by fluid extraction properties [17-18]. Colonna et al. [19] conducted a research on a combined cycle which employs a gas cycle and an internal combustion engine to provide the required energy in the absorption refrigeration cycle. This cycle can generates power and cooling, independently. Zare et al. [20] used the wasted heat in ammonia-water combined cycle to achieve the first and the second law efficiency of this cycle, respectively. By examining the benefits of ammonia water which was taken as the fluid in the combined cycle power plant, Dejfors et al. [21] achieved greater efficiency compared with the Rankine cycle. Goswami et al. [22] examined the parametric effects on Rankine power generation combined cycle and made a comprehensive comparison with the ammonia absorption cycle. Zhang Zhi et al. [23] analyzed the influence of inlet temperatures of both heat resource and cooling water on system efficiencies based on the first law and the second law of thermodynamics. The results indicated that the indices of the power recovery efficiency and the exergy efficiency of $\mathrm{KC}$ were $18.2 \%$ and $41.9 \%$ respectively, while the composite power recovery efficiency and the composite exergy efficiency of AWRC were respectively $21.1 \%$ and $43.0 \%$. G.R. Ahmadi and D. Toghrai [24] investigated the steam cycle of a power Plant with an individual unit capacity of 200 MW by using mass, energy, and exergy balance equations with the EES software. The results showed that the biggest source for wasting energy was the condenser by $69.8 \%$ while the biggest source for exergy lost was the boiler by $85.66 \%$ of the total.

In this paper, the energy-exergy analysis is conducted on the combined cycle and also on Rankine cycle for a better verification. It should be mentioned that the binary mixture is taken as ammonia-water. The EES software is utilized for performing analyses. Effective parameters on the thermodynamic performance are investigated through energy and exergy destruction, enthalpy temperature, yields, velocity, etc. The main purpose of this paper is to 
show the effects of ammonia-water dilution on pressure in the boiler and its density on ammonia-water combined cycle. The results show that generated net power increases with the increasing of the ammonia-water dilution pressure in the boiler until pressure range belong to [169.3-180] bar and after that, it starts to decrease. In addition, the increased ammonia-water dilution pressure will lead to the reduction of boiler exergy destruction and total exergy destruction as well. It also results in an increment in exergy performance coefficient (EPC).

\section{Methodology}

The ammonia-water combined cycle as shown in Fig. 1 and the Rankin cycle as shown in Fig. 2 are examined. Energy exergy analysis is conducted in both cycles. The research on the Rankine cycle is taken for the purpose of comparisons. It should be noted that the indexes of equations are chosen from the notations in Figs. 1 and 2. In order to analyze the thermal cycles, equations should be written separately for each component. Then, these equations can be solved together in a system with the temperature, pressure, and flow at every point.

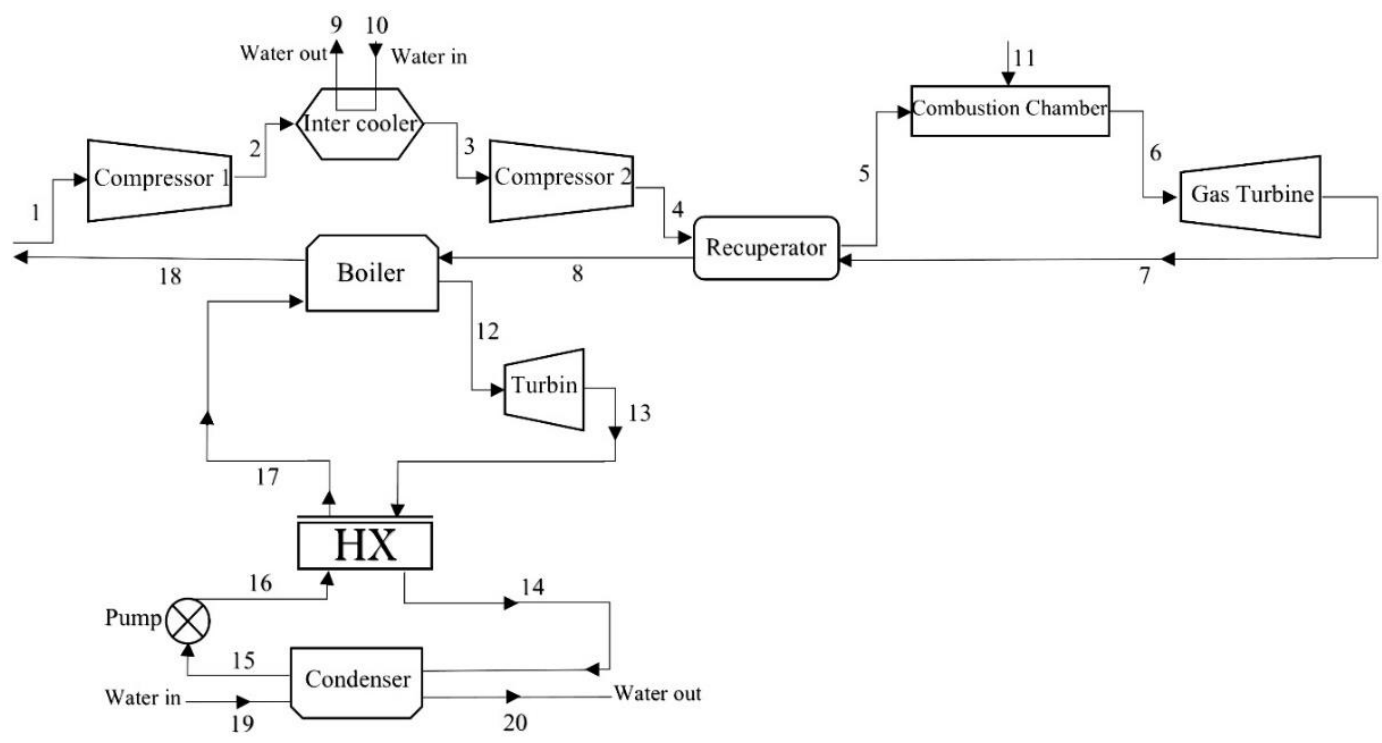

Fig. 1 Schematic diagram of ammonia-water cycle

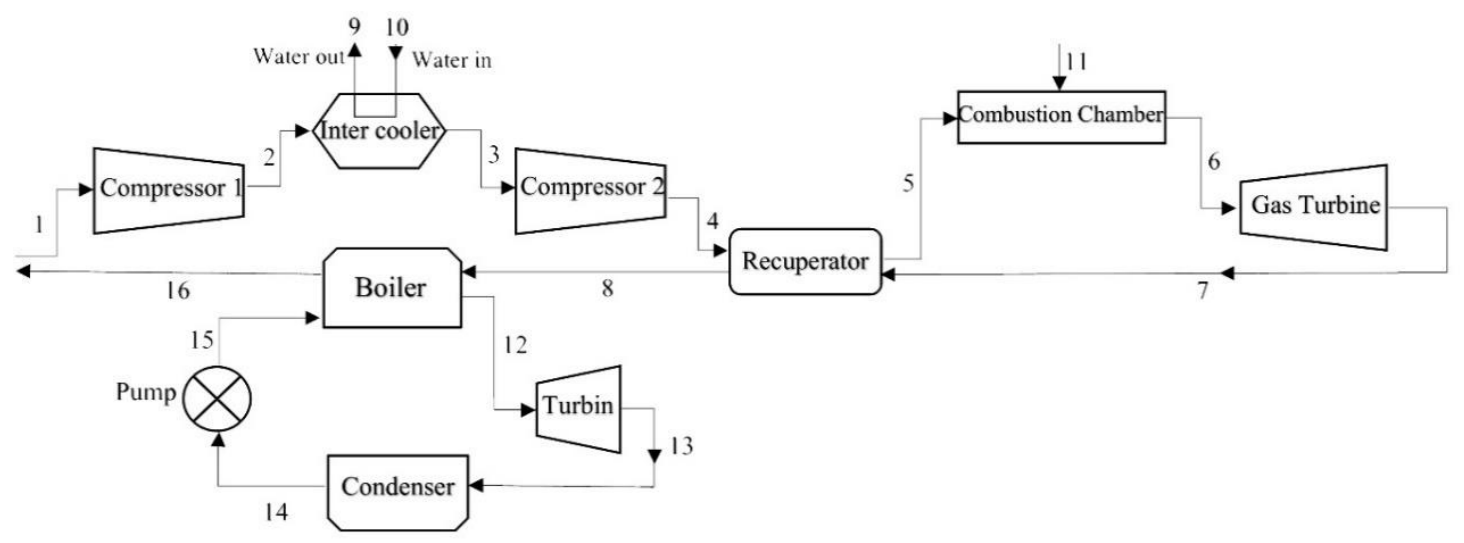

Fig. 2 Schematic diagram of Rankine cycle

In general, the energy equation is assumed to be the volume control for each component which can be written as follows:

$$
\dot{Q}+\dot{n}_{i} \overline{h_{i}}=\dot{W}+\dot{n}_{e} \overline{h_{e}}
$$

Exergy balance equation for each component is shown as follows:

$$
\dot{E}_{\text {in }}+\sum \dot{Q}_{i}\left(1-\frac{T_{0}}{T_{i}}\right)=\dot{E}_{\text {out }}+\dot{W}+\dot{E}_{D}
$$

where $E$ is the total exergy at each point, which is the summation of physical and chemical energies of components of each considered point.

Physical exergy of a thermodynamic system is consisted of the mechanical and the thermal exergy. The Mechanical exergy is the function of the pressure in the thermodynamic system while the thermal exergy is the function of the temperature in the thermodynamic system. Then, the physical exergy can be demonstrated in the following Eq. (3):

$$
\dot{E} x^{p h}=\sum\left\{n_{i}\left[\left(h-h_{0}\right)-T_{0}\left(s-s_{0}\right)\right]\right\} .
$$


The Chemical exergy is equal to the maximum of produced work while chemical species of the thermodynamic system can be mixed and made using a chemical reaction with the species which are available in the environment. These chemical reactions produce extra amount of work which is the chemical exergy of the system. Chemical exergy is calculated by the following Eq. (4):

$$
\dot{E} x^{c h}=\sum_{i} n_{i} \sum_{i}\left\{x_{i} e x_{i}^{c h}+R T_{0} x_{i} \ln \left(x_{i}\right)\right\}
$$

where $e x_{i}^{c h}$ is the special chemical exergy for each of the created component in the considered system and $x_{\mathrm{i}}$ is the mole fraction of each component in the thermodynamic system. The total exergy of system is achieved as follows:

$$
E x^{t o t}=E x^{p h}+E x^{c h} .
$$

\section{The main exergy destruction mechanisms and production of entropy and enthalpy}

\subsection{Main mechanisms}

\subsubsection{Heat transfer}

Heat transfer is raised to reduce the capability of the working cycle. Since no reports have been made between the body with the higher temperature and the lower temperature, it is important to minimize the temperature variations between the heat exchangers resources in order to minimize the return-invariance of heat transfer.

\subsubsection{Integration}

Integration is an irreversible process that is raised to reduce the ability of work. Integration is inevitable in many processes such as the combustion [25].

\subsubsection{Friction}

The fluid friction is similar to the mechanical friction. The internal friction in the thermodynamic system may waste some of the energy and may prevent it to useful work [26].

\subsubsection{Strangulation}

In the strangulation process, fluid with higher pressure is converted into the working fluid with lower pressure. No work has been done and heat is not transferred during the process. Strangulation process is an irreversible process and it has the ability to reduce work [27].

\subsection{Enthalpy and entropy of different components}

The fluid of combined cycles is composed of various components. Therefore, enthalpy and entropy should be calculated by separated equations for each of point. Enthalpy of each point can be obtained from the following equation:

$$
h=\sum_{i} x_{i} h_{i},
$$

where $x_{i}$ is the mole fraction of components and $\bar{h}_{i}$ is the mole specific enthalpy of components of each point. The relevant equations for each of the components can be found in the next subsection.

\subsubsection{Compressor}

The task of the compressor is compressing, raising air pressure and inletting fuel into the cycle. The complimentary isentropic efficiency of the compressor, the specified temperature, and the inlet pressure to the turbine, can be modeled by the following equation to simulate the temperature and pressure into the output compressor [28]:

$$
P R_{c}=\frac{P_{4}}{P_{1}}
$$

And, by using the following Eq. (8), we can calculate the optimal intermediate pressure of low compressor:

$$
P_{2}=\sqrt{P_{1} P_{4}}
$$

In the low-pressure compressor, the temperature and pressure at the outlet low-pressure compressor can be calculated by using the given temperature and pressure at the inlet compressor, as follows:

$$
\begin{aligned}
& s_{1}=s_{2 s} ; \\
& \eta_{c 1}=\frac{h_{1}-h_{2 s}}{h_{1}-h_{2}} .
\end{aligned}
$$

Power requirements of low-pressure compressor are achieved by using the energy balance equation for the low-pressure compressor, as follows:

$$
\dot{W}_{c 1}=\dot{n}_{2} \overline{h_{2}}-\dot{n}_{1} \overline{h_{1}},
$$

also, exergy destruction in low-pressure compressor is obtained by the exergy balance:

$$
\dot{E} x_{D, \text { comp } 1}=\dot{E} x_{1}+\dot{W}_{c 1}-\dot{E} x_{2} \text {. }
$$

The same process will be conducted for the highpressure compressor. And then the following relations can be obtained:

$$
\begin{aligned}
& s_{3}=s_{4 s} ; \\
& \eta_{c 2}=\frac{h_{3}-h_{4 s}}{h_{3}-h_{4}} ; \\
& \dot{W}_{c 2}=\dot{n}_{4} \overline{h_{4}}-\dot{n}_{3} \overline{h_{3}} .
\end{aligned}
$$
equal to:

Exergy destruction in high-pressure compressor is

$$
\dot{E} x_{D, c o m p 2}=\dot{E} x_{3}+\dot{W}_{c 2}-\dot{E} x_{4} \text {. }
$$




\subsubsection{Intercooler (IC)}

The coefficient effect and conservation energy equations for the intercooler are needed [29] to analyze the intercooler and it can be given as follows:

$$
\epsilon_{I C}=\frac{q_{a c t}}{q_{\max }}=\frac{C_{\min } \Delta T}{C_{\min } \Delta T_{\max }}=\frac{T_{2}-T_{3}}{T_{2}-T_{9}},
$$

where $q_{a c t}$ is the transferred heat from each of the fluids; $q_{\max }$ is the possible highest transferred heat in the thermal exchanger; $C$ is the heat capacity of the flow, and $\epsilon$ is the design parameters.

$$
\dot{n}_{w}\left(\overline{h_{10}}-\overline{h_{9}}\right)=\dot{n}_{a}\left(\overline{h_{2}}-\overline{h_{3}}\right) .
$$

The destruction exergy is obtained by the exergy balance for intercooler:

$$
\dot{E} x_{D, I C}=\dot{E} x_{2}+\dot{E} x_{9}-\dot{E} x_{3}-\dot{E} x_{10} \text {. }
$$

\subsubsection{Recuperator}

Similar to the intercooler, the coefficient effect and conservation energy equations are also needed for analysis which can be written as follows [30]:

$$
\begin{gathered}
\epsilon_{R E C}=\frac{q_{a c t}}{q_{\max }}=\frac{C_{\min } \Delta T}{C_{\min } \Delta T_{\max }}=\frac{T_{5}-T_{4}}{T_{7}-T_{4}} ; \\
\left(\dot{n}_{a}+\dot{n}_{f}\right)\left(\overline{h_{7}}-\overline{h_{8}}\right)=\dot{n}_{a}\left(\overline{h_{5}}-\overline{h_{4}}\right) .
\end{gathered}
$$
follow:

Destruction exergy in the recuperator is written as

$$
\dot{E} x_{D, R E C}=\dot{E} x_{4}+\dot{E} x_{7}-\dot{E} x_{5}-\dot{E} x_{8} \text {. }
$$

\subsubsection{Combustion chamber}

Firstly, in order to analyze the combustion chamber, it is necessary to write the combustion equation for the chamber [31]:

$$
\begin{aligned}
& a \mathrm{CH}_{4}+\left(\begin{array}{l}
0.7748 \mathrm{~N}_{2}+0.2059 \mathrm{O}_{2}+ \\
+0.0003 \mathrm{CO}_{2}+0.019 \mathrm{H}_{2} \mathrm{O}
\end{array}\right) \rightarrow \\
& \rightarrow(1+a)\left(\begin{array}{l}
x_{\mathrm{N}_{2}} \mathrm{~N}_{2}+x_{\mathrm{O}_{2}} \mathrm{O}_{2}+ \\
+x_{\mathrm{CO}_{2}} \mathrm{CO}_{2}+x_{\mathrm{H}_{2} \mathrm{O}} \mathrm{H}_{2} \mathrm{O}
\end{array}\right) .
\end{aligned}
$$

The mole fractions of nitrogen, oxygen, carbon dioxide, and water vapor can be obtained by the following equations, respectively:

$$
\begin{aligned}
& x_{N_{2}}=\frac{0.7748}{1+a} ; \\
& x_{\mathrm{O}_{2}}=\frac{0.2059-2 a}{1+a} ; \\
& x_{\mathrm{CO}_{2}}=\frac{0.0003+a}{1+a} ;
\end{aligned}
$$

$$
x_{\mathrm{H}_{2} \mathrm{O}}=\frac{0.019+2 a}{1+a},
$$

where $\{a\}$ is the mole ratio of air to fuel which can be obtained by the following equation:

$$
a=\frac{\dot{n}_{f}}{\dot{n}_{a}},
$$

where $\dot{n}_{a}$ and $\dot{n}_{f}$ are defined as follows:

$$
\begin{aligned}
& \dot{n}_{a}=\frac{\dot{m}_{a}}{M_{a}} ; \\
& \dot{n}_{f}=\frac{\dot{m}_{f}}{M_{f}} .
\end{aligned}
$$
follows:

From Eqs. (29) and (30), Eq. (28) can be recast as

$$
1+a=\frac{\dot{n}_{p}}{\dot{n}_{a}}
$$

Energy conservation equation for the combustion chamber [32] can be written as follow:

$$
\overline{h_{p}}+a \overline{h_{f}}=(1+a) \overline{h_{p}}+\dot{Q}_{r},
$$

where $\dot{\mathrm{Q}}_{r}$ is the total amount of wasted heat from the combustion chamber which can be defined by the following equation:

$$
\dot{Q}_{r}=0.02 a \cdot L H V_{\mathrm{CH}_{4}},
$$

also, the relationship between the parameters $\{a\}$ and mass flow of air and fuel is given in Eq. (34):

$$
\dot{m}_{f}=a\left(\frac{M_{f}}{M_{a}}\right) \dot{m}_{a} .
$$

Exergy destruction occurs in the combustion chamber is calculated by:

$$
\dot{E} x_{D, \text { comb }}=\dot{E} x_{5}+\dot{E} x_{11}-\dot{E} x_{6} \text {. }
$$

\subsubsection{Turbine}

Suppose that the temperature and the pressure are given in advance, as a result, the enthalpy of inlet flow to the turbine and outlet pressure turbine can be determined correspondingly. The temperature and enthalpy in turbine exhaust [33-34], and turbine pressure ratio are obtained by using the following equations:

$$
\begin{aligned}
& s_{6}=s_{7 s} ; \\
& \eta_{T}=\frac{h_{6}-h_{7}}{h_{6}-h_{7 s}} ;
\end{aligned}
$$




$$
P R_{T}=\frac{P_{6}}{P_{7}}
$$

Exergy destruction in turbine and turbine output power is obtained by using the energy conservation and exergy equations:

$$
\begin{aligned}
& \dot{W}_{G T}=\left(\dot{n}_{a}+\dot{n}_{f}\right)\left(\overline{h_{6}}-\overline{h_{7}}\right) ; \\
& \dot{E} x_{D, G T}=\dot{E} x_{6}-\dot{E} x_{7}-\dot{W}_{G T} .
\end{aligned}
$$

The amounts of air and fuel mass flow entered to the cycle are achieved by using the following equation in combination with equations of combustion chamber:

$$
\left(\dot{n}_{a}+\dot{n}_{f}\right)\left(\overline{h_{6}}-\overline{h_{7}}\right)-\dot{n}_{a}\left(\overline{h_{2}}-\overline{h_{1}}\right)-\dot{n}_{a}\left(\overline{h_{4}}-\overline{h_{3}}\right)=\dot{W}_{n e t} .
$$

\subsubsection{Boilers}

The inlet and output temperature of gas in the boiler, the temperature variation between the inlet gas to the boiler and outlet water ammonia solution of the boiler are clear. As a result, the amount of mass flow of water ammonia solution is calculated by using the energy equation in the boiler, as follows:

$$
\left(\dot{n}_{a}+\dot{n}_{f}\right)\left(\overline{h_{18}}-\overline{h_{8}}\right)=\dot{m}_{{N H_{3} H_{2} O} O}\left(h_{12}-h_{17}\right) .
$$

Destruction exergy in the boiler is also calculated from the following equation:

$$
\dot{E} x_{D, b o i l e r}=\dot{E} x_{8}+\dot{E} x_{17}-\dot{E} x_{12}-\dot{E} x_{18} \text {. }
$$

\subsubsection{Pump}

The output enthalpy of the pump is calculated by using the following equation:

$$
\frac{v_{15}\left(P_{16}-P_{15}\right)}{\eta_{p}}=h_{16}-h_{15} \text {. }
$$

The right side of Eq. (44) reveals the special work that is necessary for the pump. The destruction exergy at the pump is calculated as follows:

$$
\dot{E} x_{D, p u m p}=\dot{E} x_{15}-\dot{E} x_{16}-\dot{m}_{N_{3} H_{2} O}\left(h_{16}-h_{15}\right) \text {. }
$$

\subsubsection{Heat exchanger}

Analyze of heat exchanger is similar to recuperator which requires the effect coefficient and energy conservation equations, can be written as follows:

$$
\begin{aligned}
& \epsilon_{H X}=\frac{q_{a c t}}{q_{\max }}=\frac{C_{\min } \Delta T}{C_{\text {min }} \Delta T_{\max }}=\frac{T_{13}-T_{14}}{T_{13}-T_{16}} ; \\
& h_{13}-h_{14}=h_{17}-h_{16} .
\end{aligned}
$$

The destruction exergy in the heat exchanger is as follows:

$$
E x_{D, H X}=\dot{E} x_{13}+E x_{16}-\dot{E} x_{14}-E x_{17} .
$$

Cooling water is used to keep the input ammonia water cold. By determining the mass flow, temperature and pressure of water which entered the condenser, outlet enthalpy, and destruction energy of the condenser are obtained by the following energy and exergy conservation equations:

$$
\begin{aligned}
& \dot{m}_{19}\left(h_{20}-h_{19}\right)=\dot{m}_{N H_{3} H_{2} O}\left(h_{14}-h_{15}\right) \\
& \dot{E} x_{D, \text { cond }}=\dot{E} x_{19}+\dot{E} x_{14}-\dot{E} x_{15}-\dot{E} x_{20} .
\end{aligned}
$$

lows:

Produced power into the cycle is obtained as fol-

$\dot{W}_{\mathrm{NH}_{3} \mathrm{H}_{2} \mathrm{O}}=\dot{m}_{\mathrm{NH}_{3} \mathrm{H}_{2} \mathrm{O}}\left(h_{12}-h_{13}\right)-\dot{m}_{\mathrm{NH}_{3} \mathrm{H}_{2} \mathrm{O}}\left(h_{16}-h_{15}\right)$.

The first and the second term on the right hand side of the Eq.(51) are the produced power of turbine and the consumable power of the pump, respectively.

\subsection{The overall analysis of cycle}

The thermodynamic efficiency of the gas turbine cycle is calculated as follows:

$$
\eta_{t h}=\frac{\dot{W}_{n e t}}{\dot{m}_{f} L H V} .
$$

As well as the overall efficiency of the combined cycle can be obtained from the following equation:

$$
\eta_{\text {th,overall }}=\frac{\dot{W}_{n e t}+\dot{W}_{\mathrm{NH}_{3} \mathrm{H}_{2} \mathrm{O}}}{\dot{m}_{f} L H V} .
$$

The produced power of the combined cycle including the summation of produced power in the gas turbine cycle and ammonia-water cycle is as follows:

$$
\dot{W}_{\text {overall }}=\dot{W}_{n e t}+\dot{W}_{\mathrm{NH}_{3} \mathrm{H}_{2} \mathrm{O}} .
$$

The coefficient of exergy performance for the gas turbine cycle and combined cycle which are the ratio of produced power to exergy destruction are obtained by following formula, respectively:

$$
\begin{aligned}
& E P C=\frac{\dot{W}_{n e t}}{\dot{E} x_{D, t o t, G T}} ; \\
& E P C_{\text {overall }}=\frac{\dot{W}_{n e t}+\dot{W}_{N_{3} \mathrm{H}_{2} \mathrm{O}}}{\dot{E} x_{D, t o t, G T}+\dot{E} x_{D, t o t, N H_{3} \mathrm{H}_{2} \mathrm{O}}} .
\end{aligned}
$$

Overall energy destruction in the cycle of gas turbine and cycle of generating power of ammonia water are equal to: 


$$
\begin{aligned}
& \dot{E} x_{D, t o t, G T}=\dot{E} x_{D, t o t, c o m p 1}+\dot{E} x_{D, t o t, c o m p 2}+\dot{E} x_{D, t o t, G T}+ \\
& +\dot{E} x_{D, t o t, c o m b}+\dot{E} x_{D, t o t, I C+} \dot{E} x_{D, t o t, R E C} ; \\
& \dot{E} x_{D, t o t, N H_{3} H_{2} O}=\dot{E} x_{D, \text { tot }, \text { pump }}+\dot{E} x_{D, t o t, c o n d}+ \\
& +\dot{E} x_{D, t o t, T u r}+\dot{E} x_{D, t o t, \text { boiler }} .
\end{aligned}
$$

\section{Numerical results and discussions}

\subsection{Energy and exergy analysis}

This section displays the results of the thermodynamic analysis on gas turbine combined cycle with power generation and ammonia water combined cycle. This thermodynamic cycle simulation is experimented by the EES software. Temperature, pressure, mass flow rate, enthalpy, entropy, exergy and the mole composition of each of the cycles are listed in the Tables 1and 2.

Table 1

Variables of cycle parts for fluids except ammonia-water

\begin{tabular}{|c|c|c|c|c|c|c|c|c|c|c|c|}
\cline { 2 - 13 } \multicolumn{2}{c|}{} & \multicolumn{3}{c|}{ Mole fraction } & & Exergy, \\
\cline { 2 - 13 } \multicolumn{2}{c|}{} & Fluid type & $\mathrm{H}_{2} \mathrm{O}$ & $\mathrm{CO}_{2}$ & $\mathrm{~N}_{2}$ & $\begin{array}{c}\text { Entropy, } \\
\mathrm{kJ} / \mathrm{kmol}-\mathrm{K}\end{array}$ & $\begin{array}{c}\text { Enthalpy, } \\
\mathrm{kJ} / \mathrm{kmol}\end{array}$ & $\begin{array}{c}\text { Mass, } \\
\mathrm{kg} / \mathrm{s}\end{array}$ & $\begin{array}{c}\text { Pressure, } \\
\mathrm{kPa}\end{array}$ & $\begin{array}{c}\text { Temperature, } \\
{ }^{\circ} \mathrm{C}\end{array}$ \\
\hline 1 & Gas & 1.9 & 0.03 & 77.48 & 20.59 & 0 & 199.1 & -4713 & 171 & 101.3 & 25 \\
\hline 2 & Gas & 1.9 & 0.03 & 77.48 & 20.59 & 21.66 & 201.1 & -494.9 & 171 & 320.3 & 168.3 \\
\hline 3 & Gas & 1.9 & 0.03 & 77.48 & 20.59 & 16.96 & 192.4 & -3872 & 171 & 313.9 & 53.67 \\
\hline 4 & Gas & 1.9 & 0.03 & 77.48 & 20.59 & 41.55 & 194.4 & 875.7 & 171 & 1013 & 213.4 \\
\hline 5 & Gas & 1.9 & 0.03 & 77.48 & 20.59 & 62.47 & 206.7 & 8006 & 171 & 982.6 & 446.4 \\
\hline 6 & Gas & 5.92 & 2.059 & 75.91 & 16.11 & 135.6 & 226.3 & 7514 & 172.98 & 933.5 & 950 \\
\hline 7 & Gas & 5.92 & 2.059 & 75.91 & 16.11 & 41.17 & 229.7 & -6985 & 172.98 & 108.2 & 524.1 \\
\hline 8 & Gas & 5.92 & 2.059 & 75.91 & 16.11 & 16.65 & 219.7 & -14000 & 172.98 & 105 & 304.1 \\
\hline 9 & Water & & & & & 0 & 6.61 & 1889 & 200 & 101.3 & 25 \\
\hline 10 & Water & & & & 0.7727 & 12.47 & 3704 & 200 & 101.3 & 49.09 \\
\hline 11 & Methane & & & & & 109.6 & -21.01 & -189.3 & 1.98 & 1200 & 25 \\
\hline 18 & Gas & 5.92 & 2.059 & 75.91 & 16.11 & 2.896 & 207.5 & -19889 & 172.98 & 102 & 110 \\
\hline
\end{tabular}

Table 2

Variables of cycle parts for ammonia water

\begin{tabular}{|c|c|c|c|c|c|c|c|c|}
\hline & Fluid type & $\begin{array}{c}\text { Ammonia water } \\
\text { density, } \%\end{array}$ & $\begin{array}{c}\text { Exergy, } \\
\mathrm{MW}\end{array}$ & $\begin{array}{c}\text { Entropy, } \\
\mathrm{kJ} / \mathrm{kmol}-\mathrm{K}\end{array}$ & $\begin{array}{c}\text { Enthalpy, } \\
\mathrm{kJ} / \mathrm{kmol}\end{array}$ & $\begin{array}{c}\text { Mass, } \\
\mathrm{kg} / \mathrm{s}\end{array}$ & $\begin{array}{c}\text { Pressure, } \\
\text { Bar }\end{array}$ & $\begin{array}{c}\text { Temperature, } \\
\mathrm{K}\end{array}$ \\
\hline 12 & Ammonia water & 95 & 18.02 & 5.319 & 1945 & 26.85 & 40 & 547.2 \\
\hline 13 & Ammonia water & 95 & 11.41 & 5.406 & 1725 & 26.85 & 12.86 & 449.3 \\
\hline 14 & Ammonia water & 95 & 8.73 & 4.151 & 1251 & 26.85 & 12.86 & 337.1 \\
\hline 15 & Ammonia water & 95 & 7.218 & 0.579 & 129.4 & 26.85 & 12.86 & 308.2 \\
\hline 16 & Ammonia water & 95 & 7.337 & 0.5818 & 134.7 & 26.85 & 40 & 309.1 \\
\hline 17 & Ammonia water & 95 & 8.942 & 1.972 & 608.8 & 26.85 & 40 & 354.9 \\
\hline
\end{tabular}

Preliminary results or the basic mode for the combined cycle is displayed in Table 3 . As can be seen that by adding the ammonia water power generation cycle into the whole system $16.46 \%$ percent of power generated in the gas cycle turbine can be produced in the ammonia water combi- ned cycle. It is also observed that by this combined cycle, the efficiency will be increased about $5.81 \%$ compared with the efficiency of gas turbines. Exergy destruction rate is displayed in Table 4 separately according to the output of combined cycle.

Table 3

Preliminary results for ammonia water combined cycle

\begin{tabular}{|l|c|}
\hline Pure power generation in Rankine cycle, $\mathrm{kW}$ & 35000 \\
\hline Pure power generation in power generation combined cycle, $\mathrm{kW}$ & 5763 \\
\hline Turbine produced power in ammonia water combined cycle & 5905 \\
\hline Pump power consumption in ammonia water combined cycle & 142.3 \\
\hline Molar ratio of fuel to inlet air & 0.02071 \\
\hline Thermodynamic efficiency of gas turbine combined cycle, \% & 35.29 \\
\hline Thermodynamic efficiency of combined cycle, \% & 41.1 \\
\hline Mass flow of inlet fuel to the cycle, $\mathrm{kg} / \mathrm{s}$ & 1.983 \\
\hline Mass flow of inlet air to the cycle, $\mathrm{kg} / \mathrm{s}$ & 171 \\
\hline Mass flow of ammonia water in ammonia water combined cycle, $\mathrm{kg} / \mathrm{s}$ & 26.85 \\
\hline Exergy performance efficient of gas turbine cycle & 0.6125 \\
\hline Exergy performance efficient of combined cycle & 0.6334 \\
\hline Exergy destruction rate gas turbine cycle, $\mathrm{kW}$ & 57150 \\
\hline Exergy destruction rate of ammonia water cycle, $\mathrm{kW}$ & 7215 \\
\hline
\end{tabular}


Exergy destruction rate

\begin{tabular}{|c|c|c|}
\hline Cycle components & Exergy destruction percentage, $\%$ & Exergy destruction rate, MW \\
\hline combustion chamber & 56.57 & 36.41 \\
\hline Low pressure compressor & 5.46 & 3.515 \\
\hline High-pressure compressors & 5.54 & 3.568 \\
\hline Gas turbines & 9.53 & 3.137 \\
\hline Recuperator & 5.58 & 3.595 \\
\hline Intercooler & 6.09 & 4.679 \\
\hline Boilers & 7.27 & 0.7322 \\
\hline Condenser & 1.137 & 1.078 \\
\hline Heat Exchanger & 1.67 & 0.7033 \\
\hline Turbine & 1.09 & 0.02236 \\
\hline Pumps & 0.034 & \\
\hline
\end{tabular}

As can be seen in Table 4, the combustion chamber due to the irreversible nature of combustion has highest destruction rate of exergy and the pump has the lowest percentage of destruction. After combustion chamber, gas tur- bines and boilers are in next ranking. And also we can observe that the high and low-pressure compressors and recuperator have almost the same exergy destruction ratio. The exergy destruction ratio for each component is shown in Fig. 3.

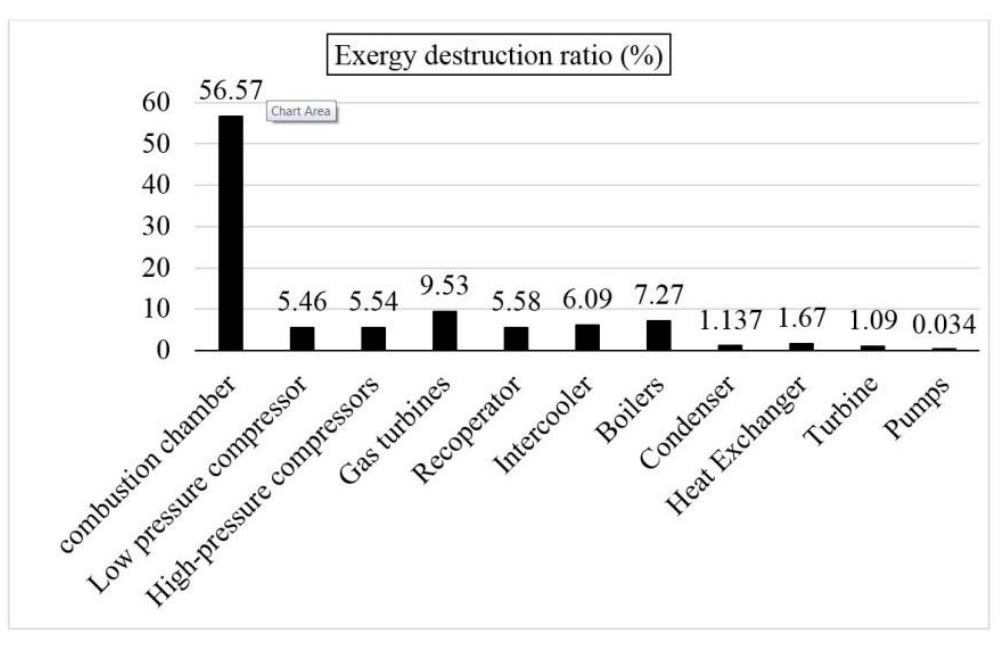

Fig. 3 Exergy destruction ratio for each component

Table 5

Variables of cycle parts for Rankine combined cycle

\begin{tabular}{|c|c|c|c|c|c|c|c|}
\hline & Fluid type & $\begin{array}{c}\text { Exergy, } \\
\text { MW }\end{array}$ & $\begin{array}{c}\text { Entropy, } \\
\mathrm{kJ} / \mathrm{kmol}-\mathrm{K}\end{array}$ & $\begin{array}{c}\text { Enthalpy, } \\
\mathrm{kJ} / \mathrm{kmol}\end{array}$ & $\begin{array}{c}\text { Mass, } \\
\mathrm{kg} / \mathrm{s}\end{array}$ & $\begin{array}{c}\text { Pressure, } \\
\mathrm{kPa}\end{array}$ & $\begin{array}{c}\text { Temperature, } \\
\mathrm{C}\end{array}$ \\
\hline $\mathbf{1 2}$ & Water & 12.77 & 122.4 & 53624 & 13.36 & 1554 & 274.1 \\
\hline $\mathbf{1 3}$ & Water & 3.787 & 127.8 & 43128 & 13.36 & 30 & 69.09 \\
\hline $\mathbf{1 4}$ & Water & 0.165 & 17 & 5210 & 13.36 & 30 & 69.09 \\
\hline $\mathbf{1 5}$ & Water & 0.1863 & 17.02 & 5243 & 13.36 & 1554 & 69.23 \\
\hline
\end{tabular}

Preliminary results for Rankine combined cycle

Table 6

\begin{tabular}{|l|c|}
\hline Evaporator temperature, ${ }^{\circ} \mathrm{C}$ & 200 \\
\hline Pure power generation in Rankine cycle, $\mathrm{kW}$ & 7758 \\
\hline Turbine power generation in Rankine cycle, $\mathrm{kW}$ & 7783 \\
\hline Pumping power in the Rankine cycle, $\mathrm{kW}$ & 24.48 \\
\hline Thermodynamic efficiency of gas turbine cycle, $\%$ & 35.29 \\
\hline Thermodynamic efficiency of gas turbine combined cycle and Rankine cycle, \% & 43.11 \\
\hline Mass flow of steam in Rankine cycle, kg/s & 13.36 \\
\hline Exergy performance factoring Gas Turbine Combined cycle and Rankine cycle & 0.6775 \\
\hline Exergy destruction rate of Rankine cycle, $\mathrm{kW}$ & 6148 \\
\hline
\end{tabular}


If the Rankine cycle is used instead of the ammonia water power cycle, the results will be shown in Tables 5 and 6 . The inlet and outlet gas from the boiler for both ammonia water, and the Rankine cycle has been assumed to be the same. As it can be seen in the base case, the produced power generation in ammonia water combined cycle is less than the Rankine cycle. In certain temperature, pressure, and conditions, the ammonia water cycle power generation water can be much higher than the maximum of power generation in the Rankine cycle.

4.2. The results on the effect of ammonia-water dilution pressure in boiler on the combined cycle

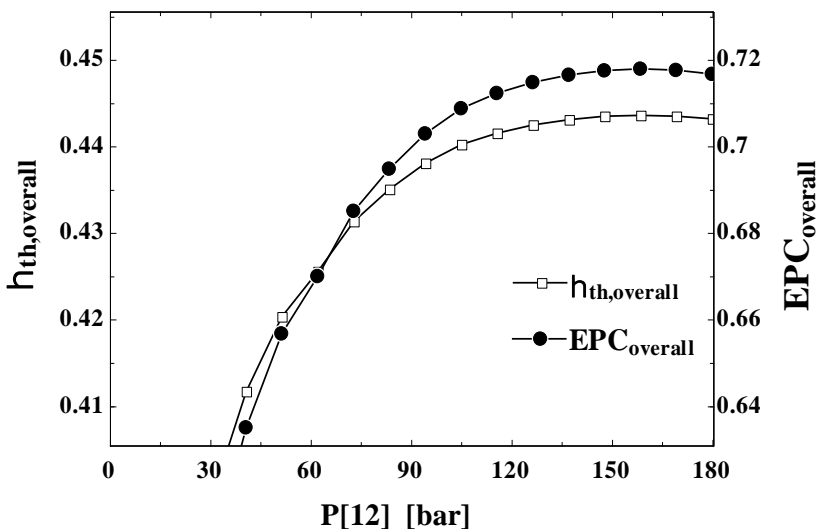

a

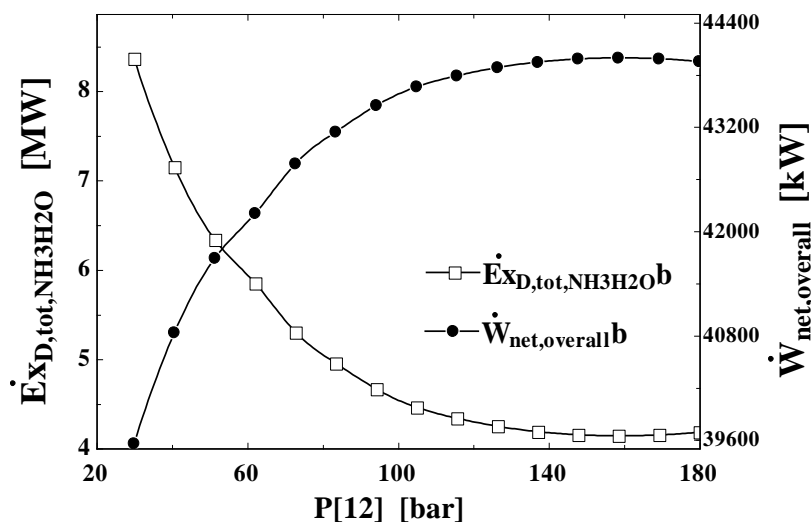

b

Fig. 4 The effects of ammonia-water dilution pressure in boiler on the thermodynamic performance of combined cycle: a - the changes of ammonia-water dilution pressure to exergy performance coefficient and overall thermal efficiency; $b$ - the changes of ammonia-water dilution pressure to destruction exergy of ammonia water combined cycle and overall pure produced power

It is obvious that by increasing the ammonia-water dilution pressure in the boiler, the net power generation of ammonia water combined cycle will be increased. This trend continues until pressure range[169.3 - 180]bar, and after that, it starts to be reduced. Hence, it is observed that thermodynamic efficiency of combined cycle will be increased and then after the above mentioned point interval the efficiency will be decreased. Moreover, it is also shown that with the increasing of pressure of ammonia water dilution in boiler causes reduction of destruction exergy and due to the significant effect of boiler exergy in the whole cycle, destruction exergy reduction of the whole cycle will occur. Based on the above description, the exergy performance coefficient (EPC) will increase corresponding to the destruction exergy increment in the whole cycle.

4.3. The results on the effect of ammonia-water density on the combined cycle

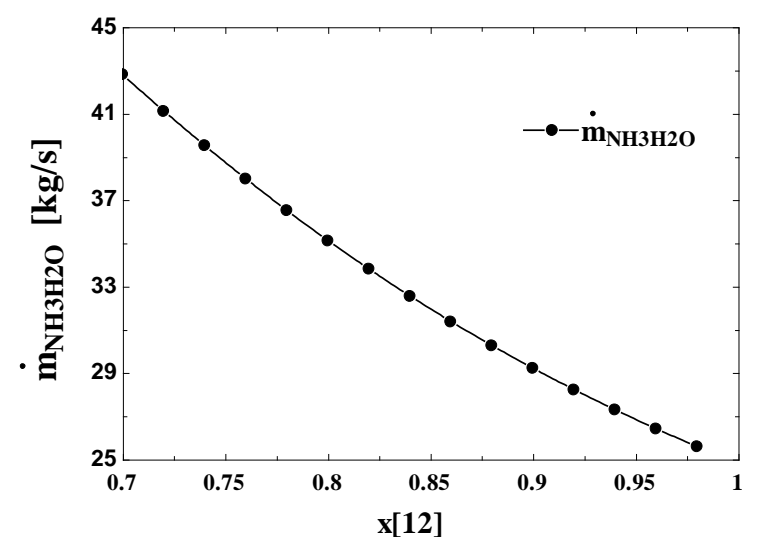

a

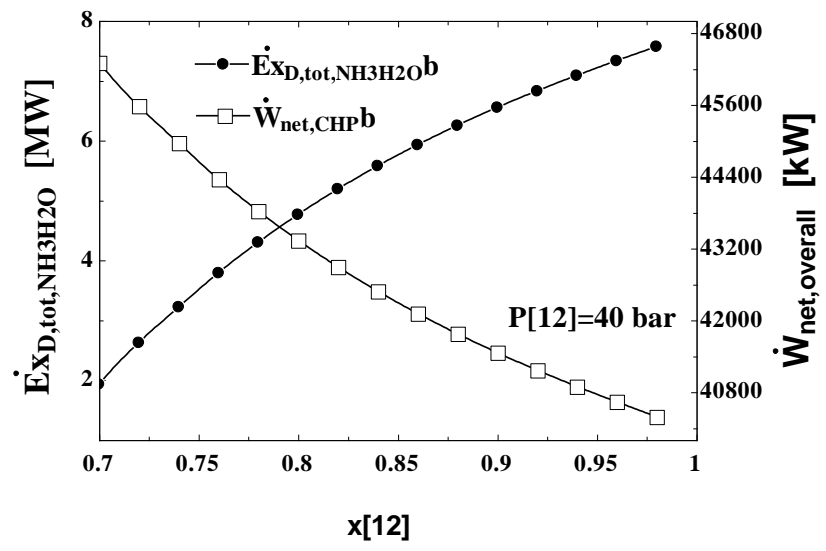

b

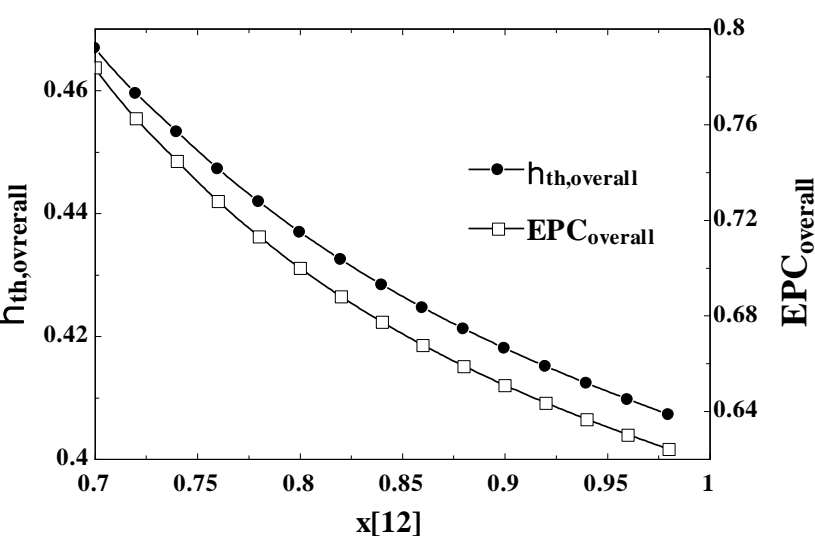

c

Fig. 5 The effects on ammonia-water density on the thermodynamic performance of combined cycle: a - the changes of ammonia-water density to mass flow rate of ammonia water cycle; $b$ - the changes of ammonia-water density to total exergy destruction and pure produced power; $\mathrm{c}$ - the changes of ammonia-water density to Exergy performance coefficient (EPC) and overall thermodynamic efficiency

It is observed that with the increasing of the density of ammonia-water will lead to the reduction of mass flow 
rate of ammonia-water dilution in the cycle. Thereby, by reducing the mass flow of dilution, it will cause net produced power generation in ammonia-water power cycle. And generally it will cause the reduction of net power generation in combined cycle.

The increased concentration of ammonia-water dilution will lead to the increasing of the destruction exergy in the boiler and the total destruction exergy in ammonia-water power generation cycle. By giving the above explanation, decreasing the production power of ammonia-water cycle will cause the reduction of thermodynamic efficiency of combined cycle. Whereas, the increasing of exergy destruction in ammonia-water power generation cycle will cause reduction of exergy performance coefficient in the whole cycle.

\section{Conclusions}

1. By increasing the ammonia-water dilution pressure in the boiler, the net power generation of ammonia water combined cycle and the thermodynamic efficiency of combined cycle will be increased. This trend continues until pressure range [169.3 - 180] bar and after that, it starts to be reduced.

2. The increasing pressure of ammonia water dilution in boiler will cause the reduction of destruction exergy. And due to the significant effect of boiler exergy in the whole cycle, destruction exergy reduction of the whole cycle will be occurred. Then, the exergy performance coefficient (EPC) will be increased corresponding to the destruction exergy increment in the whole cycle.

3. Increasing the density of ammonia-water will lead to the reduction of mass flow rate of ammonia-water dilution in the cycle. Thereby, reducing the mass flow of dilution will result in the net produced power generation in ammonia-water power cycle and generally it will result in the reduction of net power generation in combined cycle.

4. The increasing concentration of ammonia-water dilution will lead to the increasing the destruction exergy in the boiler and the total destruction exergy in ammonia-water power generation cycle. Decreasing the production power of ammonia-water cycle will lead to the reduction of thermodynamic efficiency of combined cycle. Whereas, the increasing of exergy destruction in ammonia-water power generation cycle will lead to the reduction of exergy performance coefficient in the whole cycle.

5. By adding the ammonia water power generation cycle into the whole system to recycle heat from the gas turbine cycle, $16.46 \%$ percent of power generated in the gas cycle turbine can be produced in the ammonia water combined cycle.

6. By the proposed combined cycle, the efficiency will be increased about $5.81 \%$ compared with the efficiency of gas turbines. Exergy destruction rate is displayed in Table 4 separately according to the output of combined cycle.

7. The combustion chamber has the lowest percentage of destruction due to the irreversible nature of combustion has highest destruction rate of exergy and pump.

8. Produced power generation in ammonia water combined cycle is less than the Rankine cycle. In certain temperature, pressure, and conditions, the ammonia water cycle power generation can be higher than the maximum of the power generation in the Rankine cycle.

\section{Acknowledgment}

This research investigation was supported by NSFC Funds (Nos. 11302069, 11372097), the 111 project under Grant B12032.

\section{References}

1. Schönnenbeck, C.; Trouvé, G.; Valente, M.; et al. 2016. Combustion tests of grape marc in a multi-fuel domestic boiler, Fuel 180: 324-331.

http://dx.doi.org/10.1016/j.fuel.2016.04.034.

2. Athari, H.; Soltani, S.; Rosen, M.A.; et al. 2016. Gas turbine steam injection and combined power cycles using fog inlet cooling and biomass fuel: A thermodynamic assessment, Renewable Energy 92: 95-103. http://dx.doi.org/10.1016/j.renene.2016.01.097.

3. Sivakumar, L.; Jims, S.H.; Dharmalingam, S. 2016. An investigation on the efficacy of classical tuning algorithm to satisfy advanced requirements: control of main steam pressure during fuel switching and load disturbances in coal fired boilers, Ifac Papersonline 49(1): 443449. http://dx.doi.org/10.1016/j.ifacol.2016.03.094.

4. Talukdar, K.; Gogoi, T.K. 2016. Exergy analysis of a combined vapor power cycle and boiler flue gas driven double effect water-LiBr absorption refrigeration system, Energy Conversion and Management 108: 468477.

http://dx.doi.org/10.1016/j.enconman.2015.11.020.

5. Rajović, V.; Kiss, F.; Maravić, N.; et al. 2016. Environmental flows and life cycle assessment of associated petroleum gas utilization via combined heat and power plants and heat boilers at oil fields, Energy Conversion \& Management 118: 96-104. http://dx.doi.org/10.1016/j.enconman.2016.03.084.

6. Promes, E.J.O.; Woudstra, T.; Schoenmakers, L.; et al. 2015. Thermodynamic evaluation and experimental validation of $253 \mathrm{MW}$ Integrated Coal Gasification Combined Cycle power plant in Buggenum, Netherlands, Applied Energy 155: 181-194. http://dx.doi.org/10.1016/j.apenergy.2015.05.006.

7. Yağlı, H.; Koç, Y.; Koç, A.; et al. 2016. Parametric optimization and exergetic analysis comparison of subcritical and supercritical organic Rankine cycle (ORC) for biogas fuelled combined heat and power (CHP) engine exhaust gas waste heat, Energy 111: 923-932. http://dx.doi.org/10.1016/j.energy.2016.05.119.

8. Ponce, C.V.; Sáez, D.; Bordons, C.; et al. 2016. Dynamic simulator and model predictive control of an integrated solar combined cycle plant, Energy 109: 974-986. http://dx.doi.org/10.1016/j.energy.2016.04.129.

9. Shokrollahi, H.; Avazpour, L. 2016. Influence of intrinsic parameters on the particle size of magnetic spinel nanoparticles synthesized by wet chemical methods, Particuology 26: 32-39.

http://dx.doi.org/10.1016/j.partic.2015.10.004.

10.Pakma, O.; Özdemir, C.; Kariper, İ.A.; et al. 2016. Wet chemical methods for producing mixing crystalline phase $\mathrm{ZrO} 2$ thin film, Applied Surface Science 377: 159-166. http://dx.doi.org/10.1016/j.apsusc.2016.03.107.

11.Alépée, N.; Adriaens, E.; Grandidier, M.H.; et al. 2016. Multi-laboratory evaluation of SkinEthic HCE test 
method for testing serious eye damage/eye irritation using solid chemicals and overall performance of the test method with regard to solid and liquid chemicals testing, Toxicology in Vitro 34: 55-70. http://dx.doi.org/10.1016/j.tiv.2016.02.014.

12. Nannoni, F.; Protano, G. 2016. Chemical and biological methods to evaluate the availability of heavy metals in soils of the Siena urban area (Italy), Science of the Total Environment 568: 1-10. http://dx.doi.org/10.1016/j.scitotenv.2016.05.208.

13. Kalina, A.I. 1984. Combined-cycle system with novel bottoming cycle, Journal of Engineering for Gas Turbines \& Power 106(4): 737-742. http://dx.doi.org/10.1115/1.3239632.

14. Goswami, D.Y. 1995. Solar thermal power-status and future directions, Asme-Ishmt Heat and MASS Transfer Conference, Mangalore, India, 57-60.

15. Ibrahim, O.M.; Klein, S.A. 1996. 96/02216 Absorption power cycles, Fuel \& Energy Abstracts 37(2): 149. http://dx.doi.org/10.1016/0360-5442(95)00083-6.

16.Hasan, A.A.; Goswami, D.Y.; Vijayaraghavan, S. 2002. First and second law analysis of a new power and refrigeration thermodynamic cycle using a solar heat source, Solar Energy 73(5): 385-393. http://dx.doi.org/10.3103/S0003701X14020066.

17. Wang, J.; Dai, Y.; Lin, G. 2008. Parametric analysis and optimization for a combined power and refrigeration cycle, Applied Energy 85(11): 1071-1085. http://dx.doi.org/10.1016/j.apenergy.2008.02.014.

18. Frutiger, J.; Andreasen, J.; Liu, W.; et al. 2016. Working fluid selection for organic Rankine cycles Impact of uncertainty of fluid properties, Energy 109: 987-997. http://dx.doi.org/10.1016/j.energy.2016.05.010.

19. Colonna, P.; Gabrielli, S. 2003. Industrial trigeneration using ammonia-water absorption refrigeration systems (AAR), Applied Thermal Engineering 23(4): 381-396. http://dx.doi.org/10.1016/S1359-4311(02)00212-0.

20.Zare, V.; Mahmoudi, S.M.S.; Yari, M. 2012. Ammonia-water cogeneration cycle for utilizing waste heat from the GT-MHR plant, Applied Thermal Engineering, 48(26): 176-185.

http://dx.doi.org/10.1016/j.applthermaleng.2012.05.009

21.Dejfors, C.; Thorin, E.; Svedberg, G. 1988. Ammonia-water power cycles for direct-fired cogeneration applications, Energy Conversion \& Management 39(1618): $1675-1681$. http://dx.doi.org/10.1016/S0196-8904(98)00087-9.

22. Goswami, D.Y.; Stefanakos, E.; Rahman, M.M. 2010. Analysis of power and cooling cogeneration using ammonia-water mixture, Energy 35(12): 4649-4657. http://dx.doi.org/10.1016/j.energy.2010.09.042.

23.Zhang, Z.; Guo, Z.; Chen, Y.; et al. 2015. Power generation and heating performances of integrated system of ammonia-water Kalina-Rankine cycle, Energy Conversion \& Management 92: 517-522. http://dx.doi.org/10.1016/j.enconman.2014.12.084.

24.Ahmadi, G.R; Toghraie, D. 2016. Energy and exergy analysis of Montazeri Steam Power Plant in Iran, Renewable \& Sustainable Energy Reviews 56: 454-463. http://dx.doi.org/10.1016/j.rser.2015.11.074.

25. Hagi, H.; Moullec, Y.L.; Nemer, M.; et al. 2014. Performance assessment of first generation oxy-coal power plants through an exergy-based process integration methodology, Energy 69(5): 272-284. http://dx.doi.org/10.1016/j.energy.2014.03.008.

26. Gonca, G. 2016. Thermodynamic analysis and performance maps for the irreversible Dual-Atkinson cycle engine (DACE) with considerations of temperature-dependent specific heats, heat transfer and friction losses, Energy Conversion \& Management 111: 205-216. http://dx.doi.org/10.1016/j.enconman.2015.12.059.

27. Bejan, A. 2015. Heatlines (1983) versus synergy (1998), International Journal of Heat \& Mass Transfer 81: 654658.

http://dx.doi.org/10.1016/j.ijheatmasstransfer.2015.01.106.

28. Maddox, R.N.; Erbar, E.H. 1985. Gas Conditioning And Processing, Vol. 3, Penn Well Books Tulsa Ok, 2.

29. Li, W. 2013. Optimal analysis of gas cooler and intercooler for two-stage $\mathrm{CO} 2$, trans-critical refrigeration system, Energy Conversion \& Management 71(1) :1-11. http://dx.doi.org/10.1016/j.enconman.2013.03.024.

30. Gogoi, T.K. 2014. A combined cycle plant with air and fuel recuperator for captive power application, Part 1: Performance analysis and comparison with non-recuperated and gas turbine cycle with only air recuperator, Energy Conversion \& Management 79(2): 771-777. http://dx.doi.org/10.1016/j.enconman.2013.10.028.

31. Woschni, G. 1967. A Universally Applicable Equation for the Instantaneous Heat Transfer Coefficient in the Internal Combustion Engine, Papers; Automotive Sector. http://dx.doi.org/10.4271/670931.

32. Cheng, C.; Zhang, X. 2016. Influence of serial and parallel structures on the two-phase flow behaviors for dual combustion chambers with a propelled body, Powder Technology. http://dx.doi.org/10.1016/j.powtec.2016.07.039.

33. Guo, S.; Liu, P.; Li, Z. 2016. Estimation of exhaust steam enthalpy and steam wetness fraction for steam turbines based on data reconciliation with characteristic constraints, Computers \& Chemical Engineering 93: 2535.

http://dx.doi.org/10.1016/j.compchemeng.2016.05.019.

34. Nadir, M.; Ghenaiet, A.; Carcasci, C. 2016. Thermoeconomic optimization of heat recovery steam generator for a range of gas turbine exhaust temperatures, Applied Thermal Engineering 106: 811-826. http://dx.doi.org/10.1016/j.applthermaleng.2016.06.035 
Soheil Mohtaram, Ji Lin, Wen Chen, M.Amin Nikbakht

EVALUATING THE EFFECT OF AMMONIA-WATER DILUTION PRESSURE AND ITS DENSITY ON THERMODYNAMIC PERFORMANCE OF COMBINED CYCLES BY THE ENERGY-EXERGY ANALYSIS APPROACH

\section{S u m m a ry}

The purpose of this study is to investigate the significant effect of ammonia-water dilution pressure and density on the thermodynamic performance of ammonia-water combined cycle through energy and exergy destruction, enthalpy temperature, yields, and flow velocity. The energyexergy analysis is conducted on the ammonia water combined cycle and the Rankine cycle, respectively. Engineering Equation Solver (EES) software is utilized for performing such detailed analyses. Values and ratios regarding heat drop and exergy loss is presented in separate tables for different equipment. The results obtained by the energy-exergy analysis indicate that net power increases with the increasing ammonia-water dilution pressure in the boiler. This trend continues until pressure range reach in [169.3 - 180] bar and after that, it starts to decrease. In addition, the increasing of ammonia-water dilution pressure leads to reduction of boiler both exergy and total exergy destructions, it also results in an increment in the exergy performance coefficient (EPC). Moreover, it is also noticed that the combined cycle system improves its efficiency by about $5.81 \%$ compared with gas turbines.

Keywords: Combined cycle, ammonia-water dilution pressure, energy-exergy analysis, boiler, exergy performance coefficient (EPC).

Received September 30, 2016 Accepted April 14, 2017 